\title{
Seroprevalence of Mycobacterium avium subspecies paratuberculosis (MAP) in Goat Population of Bhubaneswar, Odisha, India
}

\author{
Sangram Biswal ${ }^{1}$, Shaswati Subhadarsini Pany ${ }^{2 *}$, Niranjana Sahoo', \\ Manju Singh ${ }^{3}$ and Shoor Vir Singh ${ }^{3}$
}

${ }^{1}$ Department of Veterinary Epidemiology and Preventive Medicine, College of Veterinary

Science and Animal Husbandry, O.U.A.T., Bhubaneswar-751003, Odisha, India

${ }^{2}$ ICAR-International Centre for Foot and Mouth Disease, Arugul, Bhubaneswar-752050, Odisha, India

${ }^{3}$ Microbiology Laboratory, Animal Health Division, Central Institute for Research on Goats, Makhdoom, PO-Farah, Mathura, India

*Corresponding author

\section{A B S T R A C T}

Keywords

Antibodies, Goats, Johne's disease, Mycobacterium avium subspecies

paratuberculosis, Odisha,

Paratuberculosis,

Seroprevalence, Small ruminants

Article Info

Accepted:

12 December 2017

Available Online:

10 January 2018
Present pilot study was the first attempt to estimate the prevalence of antibodies against Mycobacterium avium subspecies paratuberculosis (MAP) in the goat population of Odisha. A total of 22 serum samples were collected from goats in and around Bhubaneswar, Odisha and subjected to indirect ELISA by indigenous ELISA (i_ELISA) kit for the detection of antibodies against MAP in the Microbiology Laboratory, Animal Health Division, CIRG, Makhdoom. An apparent prevalence $68.19 \%(15 / 22)$ was recorded by i_ELISA where the S/P ratio of the positive control was considered to be $1(100 \%)$. The $\mathrm{S} / \mathrm{P}$ ratio of the positive samples ranged from 0.4169 to 0.6857 . The results indicate the previous exposure of the animals to MAP and suggest the need of detailed systematic sampling on a larger scale to estimate the exact prevalence of MAP in various regions of Odisha to formulate necessary preventive and control measures.

\section{Introduction}

Mycobacterium avium subspecies paratuberculosis (MAP) infection in ruminants results in chronic inflammatory condition of intestine commonly known as paratuberculosis or Johne's disease characterized by poor body condition, progressive weight loss with or without diarrhoea and emaciation(Patel and Shah,
2010). MAP has been incriminated as the cause of Crohn's disease (CD), a chronic inflammatory bowel condition in human beings (Singh et al., 2016). MAP is the cause of considerable concern to the dairy industry worldwide due to the economic losses caused by reduced milk production and food safety situation as a result of post- pasteurization survival in milk and subsequent transmission to humans (Patel and Shah, 2011). India is 
endemic to Johne's disease and there have been reports of the prevalence of MAP from different regions of the country in cattle, buffaloes, sheep, goats and humans (Singh et al., 2007, Ramalakshmi et al., 2016, Bhutediya et al., 2017). Although no such prevalence has been reported from the coastal state of Odisha in eastern India, the possibility of the introduction of MAP in the animals of the state resulting from trans-boundary movement of animals from the neighbouring affected states cannot be ruled out (Ramalakshmi et al., 2016, Bhutediya et al., 2017).Thus, the present pilot study targeted at the investigation of the presence/absence of MAP antibodies in small ruminants of Odisha.

\section{Materials and Methods}

\section{Serum samples}

A total of 22 serum samples were collected from apparently healthy goats in and around Bhubaneswar with the permission of Institutional Animal Ethical Committee and stored at $-20^{\circ} \mathrm{C}$ in the Department of Veterinary Preventive Medicine, College of Veterinary Science and Animal Husbandry, O.U.A.T, Bhubaneswar.

\section{Indirect ELISA (i_ELISA)}

The serum samples were subjected to the detection of MAP antibodies by indirect ELISA using indigenous ELISA (i_ELISA) kit provided by Microbiology Laboratory, Animal Health Division, CIRG, Makhdoom according to Singh et al., (2007) in the Microbiology Laboratory, Animal Health Division, CIRG, Makhdoom.

Briefly, $0.1 \mu \mathrm{g} /$ well of antigen, in $100 \mu \mathrm{l}$ of carbonate-bicarbonate buffer, $\mathrm{pH} 9.6$ (coating buffer) was used for coating in duplicate wells of flat bottom ELISA plates (Alto, Italy), at 4 ${ }^{\circ} \mathrm{C}$ for overnight. Plates were washed thrice with PBST (phosphate buffer saline and $0.05 \%$ Tween-20). Blocking was achieved by $200 \mu \mathrm{l}$ of $3 \%$ skimmed milk powder and incubated at $37^{\circ} \mathrm{C}$ for $1 \mathrm{~h}$. After incubation, the plates were washed thrice with PBST and $100 \mu 1$ of 1:50 diluted test serum samples in dilution buffer (PBST containing 1\% BSA) was added to each well, in duplicates and incubated for $2 \mathrm{~h}$ at $37^{\circ} \mathrm{C}$. After incubation three washings ( 5 min each) were given with PBST and $100 \mu \mathrm{l}$ of optimally diluted (1:8000) rabbit anti-goat horseradish peroxidase conjugate (Bangalore Genei, India) in PBS was added to all wells and incubated for $1 \mathrm{~h}$ at $37^{\circ} \mathrm{C}$. After incubation the plate was washed three times (5 min each) with PBST. Finally $200 \mu 1$ of freshly prepared substrate (orthophenylene diamine dihydrochloride, OPD), $5 \mathrm{mg} /$ plate in substrate buffer $(\mathrm{pH}, 7.4)$ was added to each well and incubated in dark for $20 \mathrm{~min}$ at room temperature. The absorbance was read at $450 \mathrm{~nm}$ in ELISA reader (Multiskan, Thermo-Labsystems). Positive, negative, substrate and conjugate controls were run with serum samples. Serum from the goats tested positive and negative to MAP previously were used as positive and negative controls.

The optical density measured were transformed to Sample /Positive (S/P) ratio by the formula mentioned below and the corresponding status of JD in goats was interpreted as per the instructions of Collins et al. (2002). Only the positive and strong positive were considered to be positive (Singh et al., 2014).

$$
\begin{aligned}
& \text { Sample: Positive ratio value } \\
& \qquad=\frac{\text { Optical Density of Sample }- \text { Optical density of Negative Control }}{\text { Optical Density of Positive control - Optical Density of Negative Contro] }}
\end{aligned}
$$

\section{Results and Discussion}

A total of 22 serum samples were collected from apparently healthy goats in and around 
Bhubaneswar and were subjected to the detection of MAP antibodies by the indigenous ELISA (i_ELISA) kit. Out of 22 samples in the present pilot study, 15(68.19\%) were positive, $6(27.27 \%)$ were low positive and $1(4.54 \%)$ were negative for antibodies against MAP in i_ELISA (Table 1). The S/P ratio of the positive control was considered to be $1(100 \%)$. The $\mathrm{S} / \mathrm{P}$ ratio of the positive samples ranged from 0.4169 to 0.6857 .

Johne's disease (JD) was reported in India for the first time in 1913 and it continues to be a major health problem in domestic ruminants (Singh et al., 2014). Diagnosis and control of disease in sub-clinically infected animals is extremely challenging, since the disease gets transmitted prior to the development of clinical signs (Mukartal et al., 2016). However, most accurate and informative test results are often based on antibody detection using ELISA test (Singh et al., 2007). A total of 22 serum samples were collected from apparently healthy goats in and around Bhubaneswar and were subjected to the detection of MAP antibodies by the indigenous ELISA (i_ELISA) kit according to Singh et al., (2007).

The detection of MAP infection can be done in two ways viz, detection of antigen (bacilli or nucleic acid of the bacilli) by culture, $\mathrm{ZN}$ staining or PCR or detection of antibodies (serological tests). Culture is considered as gold standard but requires 12-16 weeks incubation period.

The easiest method for detection is microscopy but it requires trained personnel. Nucleic acid amplification although sensitive and less time consuming, is comparatively costly. A wide range of serological tests such as enzyme-linked immune sorbent assay (ELISA), agar gel immunodiffusion (AGID), delayed type hypersensitivity (DTH), interferon-gamma assay (IGA), fluorescence antibody test (FAT) and complement fixation test (CFT) have been successfully used for the detection of MAP infection. However, due to high sensitivity, rapidity and low cost, ELISA has emerged as the most widely used test for the screening of MAP infection in herds and flocks. Indigenous ELISA developed at Central Institute for Research on Goats (CIRG), Makhdoom, Mathura, India, has been widely used indigenous kit for the screening of animals and human samples in India (Singh et al., 2016).

On the basis of S/P ratio (Collins et al., 2002), out of 22 samples in the present pilot study, $15(68.19 \%)$ were positive, $6(27.27 \%)$ were low positive and $1(4.54 \%)$ were negative for antibodies against MAP in i_ELISA (Table 1).

The detection of antibodies to MAP in the goats of Bhubaneswar, Odisha indicates that the animals have been sensitised by previous exposure to the bacilli (Narang et al., 2017). None of the animals in the present study showed any clinical signs of the disease so the detection of specific antibodies to MAP by ELISA indicates a sub-clinical stage of infection of the animals (Bhutediya et al., 2017). Previously, a total of 157 cattle were tested for JD by single intradermal test in Cuttack, Bargarh, Puri and Jagatsinghpur districts of Odisha out of which none were positive (AICRP report, 2014-15). Thus, present pilot study is the first to report the prevalence of JD in the goat population of Odisha.

India is reported to be endemic to MAP infection and the prevalence is reported to be $63.5 \%$ in Mehasana breed of goats in South Gujarat (Singh et al., 2013), 12.22\% in goats of Kerala (Abraham et al., 2014) and $76.0 \%$ in the Bannur breed of sheep located in Mandya district of Karnataka using ELISA. 
Table.1 Percentage prevalence of MAP in serum samples by I_ELISA

\begin{tabular}{|c|c|c|}
\hline S. No. & Category of ELISA result $(\mathbf{S} / \mathbf{P}$ ratio) & No. of Samples $(\%)$ \\
\hline 1. & Strong Positive(1.0 to 10.0$)$ & 0 \\
\hline 2. & Positive( 0.4 to 0.99$)$ & $15(68.19)$ \\
\hline 3. & Low Positive( 0.25 to 0.39$)$ & $6(27.27)$ \\
\hline 4. & Suspected $(0.10$ to 0.24$)$ & 0 \\
\hline 5. & Negative( 0.00 to 0.09$)$ & $1(4.54)$ \\
\hline 6. & Total & $22(100)$ \\
\hline
\end{tabular}

Besides, prevalence of $37.7 \%$ in organized and unorganized dairy cattle herds of West Bengal (Bhutediya et al., 2017), $41.0 \%$ in buffaloes in central and North India (Audariya et al., 2016), 2.82\% in large ruminants of Krishna district of Andhra Pradesh (Didhugu et al., 2015) and $15.14 \%$ in cattle of South West Bangalore (Gupta et al., 2012) was recorded in the bovine population of different regions of India. The difference in prevalence pattern of Johne's disease in the present study could be due to diversity in topography and environment, animal rearing system, and husbandry practices followed in different states of India (Bhutediya et al., 2017). Gobally, a prevalence of $16.8 \%$ was reported in two dairy goat herds in Chile (Salgado et al., 2002), 1.4\% prevalence was noted in the Boer Goat Herds in Missouri, USA (Pithua and Kollias, 2012), 83.0\% goats were positive in Ontario, Canada (Bauman et al., 2016) and $24 \%$ - $35.9 \%$ prevalence was recorded in Burdur, Southwestern Turkey (Celik and Turutoglu, 2017).

The present study reports a high apparent prevalence of MAP infection in the small ruminants of Odisha. In absence of any vaccination being practised against the disease, the detection of specific anti-MAP antibodies confirms the infection of the animals with MAP bacilli. It is possible that in absence of past prevalence of MAP, the introduction of the organism was due to transborder movement of affected animals from the neighbouring states with reported incidence of MAP infection (Didhugu et al., 2015; Bhutediya et al., 2017).

The goats in the present study did not show any clinical signs of disease which is not uncommon and is indicative of subclinical infection as in the Satge II or lepromatous stage of Johne's disease (Bharathy et al., 2014; Manning and Collins, 2001).

The bacilli can be transmitted through consumption of milk and milk products and increased level of infection in the animals increases the threat of transmission of the disease from affected animals to healthy animals and human beings. Present study reports the sero-prevalence of JD in goat population of Bhubaneswar, Odisha for the first time. The high level of infection detected in this study indicates the exposure of the animals to MAP and increases the risk of transmission to other animals and humans alike. Hence extensive systematic sampling is advocated along with culture and biotyping to detect the strain of bacilli circulating amongst the animals in order to implement effective preventive and control strategies.

\section{Acknowledgements}

The authors are grateful to ICAR-NASF for funding this study, Director, CIRG, Makhdoom and Dean, College of Veterinary and Animal Science, O.U.A.T, Bhubaneswar for granting permission to carry out this study. 


\section{References}

Abraham, A., Thomas, N., Joseph, S. and Raghavan, K.C. 2014. Comparitive study on the efficacy of ELISA and IS900 PCR for the diagnosis of paratuberculosis in goats. Biotechnology in Animal Husbandry, 30:661-667.

Annual Report 2015-16. All India Coordinated Research Project on Animal Disease Monitoring and Surveillance (AICRP on ADMAS) ICAR-National Institute of Veterinary Epidemiology and Disease Informatics, Yelahanka, Bengaluru - 64. Accessed on 14.7.2017.

Audarya, S.D., Chhabra, D., Sahzad, Singh, M., Stephen, B.J., Chaubey, K.K., Gupta, S., Sohal, J.S., Dhama, K., Mukartal, S.Y., Rathnamma, D. and Singh, S.V. 2016. Bio-incidence of bovine Johne's disease in dairy buffaloes in Central and North India using sensitive goat based indigenous ELISA kit and traditional tests. Journal of Experimental Biology and Agricultural Sciences, 4: 525-532.

Bauman, C.A., Jones-Bitton, A., Menzies, P., Toft, N., Jansen, J. and Kelton, D. 2016. Prevalence of paratuberculosis in the dairy goat and dairy sheep industries in Ontario, Canada. Can. Vet. J., 57: 169-175.

Bharathy, S., Lakshmanasami, G., Kannan, P. and Karuppanasamy, P. 2014. Goat milk as a non-invasive sample for confirmation of Mycobacterium avium subspecies paratuberculosis by IS 900 PCR. J. Adv. Vet. Anim. Res., 1: 136139.

Bhutediya, J.M., Dandapat, P., Chakrabarty, A., Das, R., Nanda, P.K., Bandyopadhyay, S. and Biswas, T.K. 2017. Prevalence of paratuberculosis in organized and unorganized dairy cattle herds in West Bengal, India. Veterinary
World, 10: 574-579.

Celik, A. and Turutoglu, H. 2017. Seroprevalence of Paratuberculosis in Cattle, Sheep and Goats in Burdur, Southwestern Turkey. Israel Journal of Veterinary Medicine, 72: 30-36.

Collins, M.T. 2002. Interpretation of a commercial bovine paratuberculosis Enzyme linked immunosorbent assay by using likelihood ratio. Clin. Diagn. Lab. Immunol., 9: 1367-1371.

Didugu, H., Ramanipushpa, R.N., Reddy, C.E.N., Devi, M.A. and Bhaskraramarajusagi, S. 2015. Mycobacterium avium subspecies paratuberculosis among bovines in Krishna district of Andhra Pradesh, India: a serological survey. Indian $J$. Anim. Health, 54: 149- 154.

Gupta, A., Rani, S.M., Agrawal, P. and Gupta, P.K. 2012. Sero-Prevalence of Paratuberculosis (Johne's disease) in Cattle Population of South-Western Bangalore Using ELISA Kit. Open Journal of Veterinary Medicine, 2: 196200.

Manning, E.J.B. and Collin, M.T. 2001. Mycobacterium avium subsp. paratuberculosis: pathogen, pathogenesis and diagnosis. Rev. Sci. tech. Off. Int. Epiz., 20: 133-150.

Mukartal, S.Y., Rathnamma, D., Narayanaswamy, H.D., Isloor, S., Singh, S., Chandranaik, B.M., Methuku, S.R., Elattuvalappil, A.M., Mallaiah, S. and Shambanna, M.S. 2016. Prevalence of Ovine Johne's disease in Bannur breed of sheep in organized farm using multiple diagnostic tests. Adv. Anim. Vet. Sci., 4: 506-512.

Narang, D., Kaur, G., Rasool, S., Chandra, M. and Sharma, N.S. 2017. Milk ELISA in Diagnosing Paratuberculosis in Cattle and Buffaloes. Int.J.Curr.Microbiol. App.Sci., 6: 3470-3477.

Patel, A. and Shah, N. 2011. Mycobacterium 
avium subsp. paratuberculosis Incidences in milk and milk products, their isolation, enumeration, characterization, and role in human health. Journal of Microbiology, Immunology and Infection, 44: 473-479.

Pithua, P. and Kollias, N.S. 2012. Estimated Prevalence of Caprine Paratuberculosis in Boer Goat Herds in Missouri, USA. Veterinary Medicine International, 2012: 1-5.

Ramalakshmi, B., Mukherjee, F., Prasad, A., Bahekar, V.S., Rana, S.K., Sharma, G.K., and Srinivasan, V.A. 2016. Isolation and molecular confirmation of Mycobacterium avium subspecies paratuberculosis in cattle and buffaloes from three states of India. Bulg. J. Vet. Med., 19: 189-199.

Salgado, M., Kruze, J. and Collins, M.T. 2007. Diagnosis of paratuberculosis by fecal culture and ELISA on milk and serum samples in two types of Chilean dairy goat herds. J. Vet. Diagn. Invest. 19: 99-102.

Singh, A.V., Chauhan, D.S., Singh, S.V., Kumar, V., Singh, A., Yadav, A. and Yadav, V.S. 2016. Current status of Mycobacterium avium subspecies paratuberculosis infection in animals \& humans in India: What needs to be done? Indian J. Med. Res., 144: 661671.

Singh, K., Chandel, B.S., Dadawala, A.I., Singh, S.V., Chauhan, H.C., Singh, B., Agrawal, N.D., Gupta, S. and Chaubey, K.K. 2013. Incidence of Mycobacterium avium subspecies paratuberculosis in Mehsana breed of goats from South Gujarat using multiple tests. Adv. Anim. Vet. Sci. 1: 28-31.

Singh, S.V., Singh, A.V., Singh, P.K., Sohal, J.S. and Singh, N.P. 2007. Evaluation of an indigenous ELISA for diagnosis of Johne's disease and its comparison with commercial kits. Indian J. Microbiol., 47:251-258.

Singh, S.V., Singh, P.K., Singh, A.V., Sohal, J.S., Kumar, N., Chaubey, K.K., Gupta, S., Rawat, K.D., Kumar, A., Bhatia, A.K., Srivastav, A.K. and Dhama, K. 2014. Bio-load and bio-type profiles of Mycobacterium avium subspecies paratuberculosis infection in the domestic livestock population endemic for Johne's disease: a survey of 28 years (1985-2013) in India. Transboundary and Emerging Diseases, 61: 1-13.

\section{How to cite this article:}

Sangram Biswal, Shaswati Subhadarsini Pany, Niranjana Sahoo, Manju Singh and Shoor Vir Singh. 2018. Seroprevalence of Mycobacterium avium subspecies paratuberculosis (MAP) in Goat Population of Bhubaneswar, Odisha, India. Int.J.Curr.Microbiol.App.Sci. 7(01): 16181623. doi: https://doi.org/10.20546/ijcmas.2018.701.196 